\title{
Plantação de Bananeira - A atentividade e a imediação como procedimentos de estudo da dança na Escola Básica Municipal Victor Miguel (Florianópolis - SC).
}

\author{
Handstanding - Attentiveness and immediation as dance study \\ procedure at Victor Miguel Municipal Basic School (Florianópolis, \\ Brazil).
}

\author{
Felipe Ferreira Ferro ${ }^{1}$ \\ Heloísa Marina da Silva ${ }^{2}$
}

Submetido em 8 de abril e aprovado em 15 de maio de 2019.

\begin{abstract}
Resumo: Este artigo analisa um projeto de ensino da dança que articulou práticas e pesquisas que ocorreram em escolas públicas da cidade de Florianópolis. Com atenção à prática da improvisação em dança, o estudo tem apetite por Pedagogias Radicais, arte relacional e atentividade na performance. Além disso, abre caminho para a investigação de formas de participação e condução de processos criativos: o que é a imediação no processo de aprendizagem da dança? A imediação pode ser como apontar outro caminho, onde o sensível e a polifonia dos afetos engendrados na experiência estão em jogo; onde prevalece a diversidade presente nos acontecimentos convidando a constelação de corpos a criar a partir dela ao invés de reiterar parâmetros regulatórios inerentes ao regime normativo da instituição escolar. Essa preocupação surge da vontade de criação de campos de estudo da dança em sua verve atual e relacional, para que possam ser ativados poderes ainda não atualizados de forma dançada, conectando a memória do passado com a vida em que nós gostaríamos de ser coletivamente. Plantar Bananeira é uma proposta de reativação do ânimo para que a vida seja criada em campos radicalmente diversos.
\end{abstract}

Palavras-chave: Imediação. Pedagogias Radicais. Pedagogias da Dança.

Abstract: This article analyses a project that is articulated with practices and research that took place in Florianópolis since 2017, in public schools. With attention to the practice of improvisation in dance, the study has an appetite for Radical Pedagogies, relational art and attentiveness in performance. In addition, opens the way for the investigation of ways of participation and conduction of creative processes, where I elaborate the axis: what is immediation in the process of learning dance? Imediation can be like pointing to another path where the sensitive, the polyphony of the affects engendered in the experience, or, situations where diversity prevails and calls us to create from it, instead of reiterating the regulatory parameters inherent to the normative regime of the school institution. This concearn appears from the aim to create fields for the study of dance in its actual and relational verve, so that we can connect with powers not yet actualized in a danced form, connecting what we call a memory of the past with 
the life in which we would like to be collectively. Plantar Bananeira is a proposition of reactivation of the mood so that life is created in radically diversity fields.

Keywords: Immediation. Radical Pedagogies. Dance Pedagogies.

Este texto é um relato de acontecimentos nascentes no campo de estágio E.B.M Victor Meireles onde pedagogias do movimento compuseram os estudos abertos na escola. $\mathrm{O}$ artigo também narra acontecimentos que atravessaram o processo pedagógico em decorrência de uma greve instaurada durante a realização do projeto. Com ênfase na força relacional irradiada no encontro, Plantação de Bananeira caminha pelas bordas de experiências que persistiram vibrando tanto em matéria quanto na virtualidade de seus movimentos. A imediação como ação pedagógica, o silêncio como estudo atencioso do campo escolar e o movimento das relações são os modos de existir pelos quais o processo de estágio é narrado.

Primeiro é importante destacar que a política da imediação não atua como contraponto à mediação. Partir da divergência poderá encerrar o caminho do estudo proposto. Deste modo, apresentamos a imediação como prática assumidamente diversa e criadora de outra perspectiva de atenção pedagógica. Antes de discorrer detalhadamente sobre o termo imediação é fundamental atentar às pessoas que este relato repercute questões que procuram compreender a experiência como lugar de onde a vida emerge, sendo está criada através da articulação das múltiplas forças que compõem o mundo: o clima, a arquitetura da sala de aula, as emoções que movem estudantes e professores etc, podem fazer parte desta multiplicidade de onde a experiência nasce. Portanto, este pensamento afasta-se da preponderância do sujeito na condução e mediação das experiências. Por este motivo é importante ressaltar que não se está invalidando a compreensão de que a vida sócio-política tem valor de criação e condução de parte das experiências que vivenciamos dia-a-dia. É justamente por saber da existência deste poder de orientação e sedimentação da experiência humana em contextos normativos que o projeto foi tramado de modo a valorizar o estudo de pedagogias que buscam radicalizar o fazer como "pensamento por direito próprio" (MANNING, 2016, p.20). O relato está orientado na direção de caminhos onde a vida é móvel e movente, ou seja, onde não há sujeito da ação: “É importante 
reiterar: o conhecedor não é o sujeito, mas o modo como as relações se abrem para os sistemas de subjetivação" (MANNING, 2016, p. 30). Ou seja, criar quando o que está em jogo é menos o indivíduo do que a relação. Um pouco mais além, este trabalho irá relatar sobre afetos aproximando-se do que Suely Rolnik nos chamou atenção ainda nos anos 90:

Em nossa condição de viventes somos constituídos pelos afetos das forças e suas relações variadas e variáveis que agitam o fluxo vital de um mundo, os quais atravessam singularmente todos os corpos que o compõem, fazendo dele um só corpo, em variação contínua, que se tenha ou não consciência disto. Podemos designar tais efeitos por afetos (ROLNIK, 1993, p.07).

Neste sentido, a frustração é uma arma neoliberal carregada de afetos que podem cristalizar relações numa composição desvitalizada. Sem recusar as dificuldades impostas sistemicamente às escolas públicas no que tange a qualidade da estrutura dos edifícios, ao valor pago por hora/aula às professoras e professores e principalmente, sem invalidar as dificuldades presentes na relação entre estudantes e professorxs, surgem questões que buscam ultrapassar estes aspectos como parâmetros únicos de análise do que é a realidade escolar e do que pode ser o ato pedagógico. Apontar para outro caminho onde o sensível e a polifonia dos afetos engendrados na experiência nos coloca em situações onde a diversidade vigora, e que também nos convida a criar ao invés de reiterar os parâmetros reguladores inerentes ao regimento normativo da instituição. Bem que poderíamos estender a compreensão deste regimento às inúmeras instâncias reguladoras da sociedade: escola, universidade, família, igreja, partidos políticos, casamento; mesmo assim, é certo que dentro de todas estas instituições existe de alguma forma algo de resistência potente e vital sendo atualizado. A rigidez destes conceitos cristaliza a compreensão em torno de concretudes que não se reafirmam na prática, pois é sabido que a norma é transbordada a todo tempo e que, como resposta a isto, práticas contentoras são empregadas constantemente. A punição e a classificação de pessoa em tipos de doença (nosologia) são métodos comuns de contenção daquilo que ultrapassa os limites da norma. Ainda que todas as questões expostas imprimam dificuldades ao ambiente escolar, é inevitável insistir que a escola é o lugar onde crianças, adolescentes, jovens, adultos e idosos se encontram diariamente durante algumas horas. Assim, podemos caminhar 
por aqui: a escola como lugar do encontro de muitas pessoas de origens distintas. São múltiplos os universos que convivendo num espaço arquitetônico público dão margem a abertura de campos de criação e aprendizagem que mesmo sob a égide do regimento escolar podem extrapolar e transpor a ordem disciplinar. É inevitável que se aprenda algo na escola, principalmente quando o assunto está à margem da norma. Também é necessário acrescentar que este aprendizado é em-ato, ou seja, no fazer. Aprende-se jogar, jogando. Falar, falando. Criar, fazendo. Imaginar, fazendo algo que exceda a realidade instaurada. Quanto ao fazer em ato e sobre a necessidade de seu desalinho com o que é pré-estabelecido, Erin Manning levanta a seguinte pergunta em Proposições para uma Pedagogia Radical, ou Como Repensar Valores: "E o que fazer das forças que são sentidas, mas que permanecem inefáveis?” (2017, p.27)

Ser professor, dar aula, conduzir um processo é permitir-se adentrar em sua própria prática, em seu próprio fazer. É através do contato com xs estudantes que a prática é revisitada, aprimorada, questionada e criada. As dúvidas e dificuldades do corpo discente estão muito próximas das enfrentadas por professorxs e mesmo que não se apresentem imediatamente como dificuldades, estas questões levantadas em sala de aula atravessam a prática como questionamentos que reposicionam as certezas. Ensinar, portanto, parece ser o mesmo que viver para balançar no fio da vida em contato com múltiplas inteligências. Perguntas desenrolam novas perguntas que são criadas no agora; por exemplo: no contexto das aulas do estágio comunitário ocorrido no segundo semestre de 2017 algumas crianças questionaram as perguntas que estavam sendo feitas. Naquela aula uma aluna perguntou se aquele momento era uma prova, algo que na opinião dela era um "aborrecimento". Esta pergunta surgiu como uma chispa que fez o professor elaborar a seguinte resposta:

- As perguntas que faço a vocês são perguntas que faço a mim no exato momento, a partir de nossa conversa. Não é uma prova, estamos pensando juntas.

No texto "Anotações sobre Pedagogias Radicais", Bianca Scliar Mancini conversando com Henri Giroux, apresenta alguns aspectos que fundamentam as pedagogias radicais. Dentre eles está "a preservação da curiosidade e da inquietação como motes para o processo pedagógico" (MANCINI, 2016, p.12). Outro ponto importante, que é parte da discussão do presente texto, afirma que "a aprendizagem deve ser 
inventada no fazer" (MANCINI, 2016, p.12). Deste modo, recorrendo novamente a esta autora, "como conceberíamos, neste caso, uma pedagogia apta a gestar transitoriedade de saberes, ainda que diante de exigências metodológicas institucionais, exigências estas que nos demandam constante avaliação dos alcances e conteúdos?” (MANCINI, 2016, p.14). Parece óbvio que a curiosidade é fundamental para a criação de um processo pedagógico, principalmente no campo das artes, no entanto, estamos propondo aqui uma radicalidade de entrega à esta curiosidade que se dedica ao movimento do pensamento. Como pode ser isso? Colocar-se atentx aos pormenores emergentes das relações em sala de aula tendo em conta a condição processual dos encontros criativos é um chamado ao mergulho na experiência, e mais, é um convite a participar das aberturas que os estudos propõem quando atentxs às relações possíveis e impossíveis. Imediar, portanto e neste caso, é confiar na riqueza do processo que se abre através de perguntas que nascem do próprio fazer. Uma pedagogia que não "decide previamente o que é útil” (MANNING, 2017, p.27) colocando-se nas bordas do acontecimento, no lugar onde o conhecimento pode ser sentido mais do que organizado, que pode ser mais movimento do que avaliação. Ainda seguindo Erin Manning, ao reconhecermos o processo como uma ecologia de acontecimentos deslocados de uma propoderância do sujeito humano como movedor do mundo, situando-nos no movimento do conhecimento através das corporificações, poderemos abrir espaço para a compreensão de que "o que precisamos não é uma nova sala de aula, nem novos estudantes, mas novas técnicas para orientar a percepção: pensar que estudar transversalmente envolve um repensar o conceito de pensamento em si mesmo" (2017, p. 28).

\section{Plantar bananeira em sala é ativar a atenção e o foco a algo presente: ossos, articulações, olhar e escuta}

Neste sentido, é exposto aqui um acontecimento inerente as aulas de estágio vivenciadas na Escola Básica Municipal Vitor Miguel, instituição situada no bairro Itacorubi da cidade de Florianópolis.

A turma notadamente permeada por intensidades que agitam a paisagem sonora da sala (gritos, criança correndo, múltiplos focos de atenção, meninas quietas sobre a 
cadeira) se mostrava resistente às atividades que demandavam foco um pouco mais concentrado. O plano da primeira de duas aulas era a realização de uma ação que exigia foco para compreensão das instruções. No entanto, todas as propostas de ação eram rapidamente sobrepostas por parte da turma; xs estudantes corriam, brincavam de luta entre si; um chegou a escalar a janela da sala gritando algo lá de cima. A trio de professorxs foi desistindo pouco a pouco de continuar solicitando silêncio e atenção: deram risada postando-se no centro da sala onde iniciaram uma conversa sobre as dificuldades daquele momento, enquanto a turma continuava com sua composição polifônica. Ao regressar para o segundo turno, um dos professores foi tomado pela decisão de que plantaria bananeira assim que entrasse na sala. Foi o que fez. Diante desta ação, aquelxs que mais criavam situações de intensidade alta e que sobrepunham as intensidades de outrxs estudantes, aproximaram-se com curiosidade: testemunhando este câmbio na atenção, professorxs e alunxs passaram a estudar posturas que exigiam equilíbrio, força, concentração e foco: a ação como um convite ao diálogo a partir do fazer. Compreendendo que ali havia espaço para o aprofundamento do estudo, uma das professoras iniciou movimentos em duo que convidavam o grupo a estudar o equilíbrio de dois corpos sustentando-se ora pelas mãos ora pelas costas. A proposição, desta maneira, foi sendo criada na medida em que alguma situação de contato físico era experimentada: Uma pessoa diante da outra, as duas de mãos dadas e braços alongados, deveriam deslocar o eixo de seus corpos de modo que, uma sustentaria a outra sem grande esforço. Acontece que deste estudo prático e espraiado, pois os focos eram múltiplos, chegou-se ao jogo tradicional Jana Cabana. Não houve acordo prévio e a partir da prática foi apresentada a possibilidade de estudo, algo que desembocou numa brincadeira tradicional. O interessante é que o estudo e a brincadeira criaram pacientemente um campo onde pouco a pouco as crianças "bagunceirxs e quietinhxs" entraram na proposição. É verdade que a participação que interagia diretamente com o jogo era flutuante, porém, surpreendemente houve um trabalho onde as intensidades estavam num balanço positivo. O campo de estudo alastrouse de modo distinto do habitual. Surge daí a discussão sobre a imediação.

Erin Manning em "Toward a politics of immediation" $(2017)^{3}$ discorre sobre o assunto. Enfatizando a experiência citada acima e conversando com a filósofa, o texto 
fortalece o pensamento de que o estudo iniciado por plantar bananeira surgiu como uma pedagogia da imediação. Também acentua que o fazer esteve tramado sobre a polifonia dos afetos e nos aponta sobre a possibilidade de condutoras e condutores de processos pedagógico-criativos se posicionarem nas imediações do acontecimento.

Sobre o estudo previamente articulado em nome do ordenamento da aprendizagem, a autora chama atenção:

Uma política da imediação não nega que os sujeitos existam e afetam como a experiência vem a ser. O que sobressai é que esses sujeitos nascem da ocasião, afetados e afetando dentro da matriz de suas condições singulares de existência. Não há mediação aqui: o sujeito não pode ser analisado, externalizado, abstraído da ocasião. Os mundos-dos-corpos são uma constelação. $\mathrm{O}$ tempo aqui não é um ambiente passivo em que o sujeito está. O tempo do sujeito não pode ser abstraído do tempo de seu surgimento. A este respeito, o sujeito só pode ser visto como fugaz, como uma aparição no ápice que enfatiza uma certa qualidade da experiência (MANNING, 2017, p.15).

Imediar, portanto, é assumir o caráter imprevisível e improvisacional do encontro, incorporando à pedagogia aspectos que lidem com as urgências dos corpos em relação. Estar em sala de aula, visitar periodicamente uma instituição escolar pública é de modo muito concreto ativar práticas radicais que podem potencializar a vida daquele espaço, principalmente quando o discurso oficial incide sobre a prática criando realidades sintonizadas ao status quo. Não há norma que impeça a imediação acontecer, ainda que os documentos oficiais imponham conteúdos e formas. Imediação não é sobre conteúdos, é sobre o como se faz e sobre desviar, é sobre criar linhas de fuga e estar no meio da experiência, mergulhado nela com atenção ao que surge através do encontro. Sobre estar no meio, Deleuze diz:

Meio não é uma média; ao contrário, é o lugar onde as coisas adquirem velocidade. Entre as coisas não designa uma correlação localizável que vai de uma para a outra e reciprocamente, mas uma direção perpendicular, um movimento transversal que as carrega uma e outra, um riacho sem início nem fim, que rói suas duas margens e adquire velocidade no meio (DELEUZE apud MORAES E JARDIM, 2017, p.24). 
Portanto, o ato de plantar bananeira que surge de uma intuição e é compreendido como uma decisão mais do que humana. Ao perseguir a questão carregada por Erin Manning de que o movimento da experiência precede a forma e que, por sua vez, a forma é apenas uma um traço ínfimo da qualidade de movimento da experiência, reiteramos a narrativa de que foi a disponibilidade à coreografia criada em sala de aula que impulsionou ação de plantar bananeira. Três movimentos de pensamento que estiveram incorporados ao acontecimento são enunciados aqui: a intuição, a experiência como movimento independente de um eu predeterminado e a forma como apenas um traço da experiência. Ainda nesta direção, destacamos a reorientação das tendências que habitavam a sala a partir de uma mudança na intensidade do gesto. Caminhando com Brian Massumi em seu livro $O$ que os animais nos ensinam sobre política recorro à brincadeira como propositora de transformações da experiência ou, como reforça Massumi "a brincadeira é feita de gestos performativos que exercem uma força transindividual” (2017, p.17).

O movimento de mudança no grau de atenção e de dedicação ao fazer gestado em sala de aula ocorreu não por uma ação isolada e elegida completamente pelxs profesorxs, mas pela relação de forças que moviam o campo. A vitalidade expressada pela ação convocou as forças que também compunham o ambiente a participar desta existência intensa e diferenciada. Em outras palavras, aquela ação atuando numa "zona de indiscernibilidade não é uma indiferenciação; em vez disso, é onde as diferenças se unem ativamente" (MASSUMI, 2017, p.19). Persistinto neste caminho, insistimos que a tomada de decisão de plantar bananeira logo no retorno à sala de aula parece ter nascido de uma sensação; parece, pois houve a sensação que impulsionou a ação de acordo com a tecnicidade incorporada naquele momento (no caso, plantar bananeira foi o caminho por onde este sentir culminou formalmente).

A intuição, ou "memória de futuro" (MANNING, 2017, p.264), portanto, chega ao texto através do movimento pelo qual houve um deslocamento para o interior do acontecimento, de modo que as existências coincidiram com o que estaria prestes a existir. Esta afirmação pode soar estranha e até incômoda a quem por ventura insista em situar a experiência nos braços da decisão meramente humana, no entanto, este estudo dedica-se a elaborar pedagogias transituacionais de criação. No texto Artimanhas: 
Coletividades emergentes e processos de individuação ${ }^{4}$, Manning destaca que "a memória do futuro torna sensíveis as mínimas vibrações - humanas e não humanas - à espreita nos interstícios da experiência.” (2017, p.264). É através desta compreensão que repercute o acontecimento relatado, pois a ação de plantar bananeira propiciou o mergulho em uma futuridade através da qual a intuição pode tocá-la: intuitivamente concidimos o movimento de nossas existências em direção à um acontecimento futuro singular que modificou a atenção das corporificações que participavam da atividade. Desta relação onde não existem as determinações de uma finalidade, concordamos com Manning ao saber que $\mathrm{x}$ professor/x ao colocar-se de cabeça para baixo pode experimentar algo íntimo e inefável da experiência: "No acontecimento, no meio, conhecemos o objeto não em sua completude, em sua forma última, mas como algo que nos inscreve na experiência". Ainda assim, é importante ressalvar que não é só o estar de ponta-cabeça que moveu o acontecimento ímpar, mas que ele foi o ponto de inflexão onde o campo pode vivenciar uma diferença em sua existência, algo que aglutinou a sala de aula num fluxo de estudos da corporalidade e de sua transformação em um jogo conhecido pela turma.

Por outro lado, é evidente que a presença da mediação durante o acontecimento; a imediação não é um contraponto à mediação. A imediação requer outro estado de atenção e não busca suprimir a mediação, embora possa ser interessante um estudo pedagógicoartístico que radicalize ainda mais a imediação como procedimento de encontro com o movimento de criação em espaços escolares. Sobre situações que se apresentam durante a aula é comum haver a necessidade de mediações de conversas sobre homofobia na escola, sobre machismo e violência etc, porém, nada disso desarticula a co-composição das micro-relações que vão se criando intensamente através do movimento aderido a elas.

\section{A pausa para a greve e a reunião de professoxs em espaços públicos: Silêncio, escuta e ação coletiva emergente.}

Reiterando a força das reorientações, tanto sócio-políticas quando no plano de composição micropolítico, foi instaurado um movimento de greve por parte dxs professorxs da rede pública muncipal, colocando xs autorxs deste texto em contato direto com as intensidades e movimentos criados a partir de decisão de paralisação das 
atividades dentro das escolas. Buscando possibilitar o enlace entre as duas condições, aulas em sala e participação nos atos grevistas, persistimos atentxs aos acontecimentos que escapoliram aos movimentos habituais presentes nas duas situações. Da sala de aula à calçada diante do Câmara Municipal de Vereadores, novas possibilidades de existência são criadas em ato.

Podemos pensar numa greve como ato pedagógico que vai além da causa político-social? De fato, é de suma importância e necessária a luta em torno da defesa do ensino público. Servidores Públicos da cidade de Florianópolis paralisaram suas atividades por mais de 30 dias entre os meses de maio e junho de 2017. Em pauta, a implementação de Organizações Sociais (OS's) sem consulta pública e por vias nãoconstitucionais por parte da administração pública municipal. Caracterizando-se como privatização e precarização do serviço público, tal medida desencadeou a referida greve. No entanto, estamos discutindo aqui aspectos sutis de experiências vivenciadas durante um ato público. O que uma manifestação pública ensina sobre pedagogias radicais?

Enquanto a manifestação acontecia do lado de fora da câmara, alguns sindicalistas procuravam inflamar do alto do trio elétrico as muitas pessoas que estavam no chão. Eram muitas ocupando o calçadão dianteiro e parte das vias laterais que margeiam o edifício. A voz vinda do carro de som se misturava ao batuque de um pequeno grupo de pessoas disposto na ponta oposta ao carro; o som das muitas vozes se misturava compondo a paisagem sonora daquela greve. Em dado momento um grupo grande de pessoas solicitava aos gritos que o sistema de rádio da câmara fosse ligado - este sistema emite para o lado de fora do prédio as falas dos vereadores dentro da plenária. Deste modo, o aparelho foi ligado no momento em que um vereador discursava a favor das pautas apresentadas pelxs manifestantes, ainda assim, as vozes no carro de som não cessavam; as pessoas que estavam no chão gritavam pedindo silêncio para que o discurso fosse ouvido. Ali, naquele instante foi experimentado algo inusitado: o silêncio da multidão para escutar o rádio. $\mathrm{O}$ silêncio que se fez sentir para além da necessidade de ouvir o discurso, ainda que ele estivesse sendo emitido pelo aparelho. Algo a mais aconteceu no entorno daquela multidão que silenciou, não entanto, não saberíamos sentenciar precisamente o que era este algo. A mudança do modo agitado para o estado silente criou uma atmosfera de densidade diferente da anterior, algo distinto 
se instaurou compondo outro tempo, ampliando outra duração para aquele encontro. Talvez tenha surgido aquilo que é tão ansiado nas salas de aula: o silêncio e o foco. O excesso das falas que vinham do trio elétrico que buscavam assanhar a multidão e esta, num ato coletivo de ajustamento das intensidades, solicitou silêncio momentâneo aos líderes sindicalistas para poder conferir o teor de outro discurso que saia do rádio. Porém, podemos nos atentar à mudança repentina ativada por este gesto: a diminuição no volume sonoro produzido pela multidão intensificou sua presença, enquanto que a situação anterior, ruidosa, dispersava a atenção pulverizando as intensidades para além do coletivo de entes presentes ali: a presença da multidão se fez mais intensa quando a paisagem sonora se tornou menos ruidosa. Sem a pretensão de excluir a importância dos ruídos num ato público, evocamos o momento onde o silêncio foi solicitado como foco deste estudo. $\mathrm{O}$ enfoque das duas circunstâncias, silêncio em sala e o silêncio na manifestação, está no que se acentua quando algo imprevisível se realiza. Tanto o acontecimento do plantar bananeira quanto o pedido de silêncio feito pela multidão, ambos vindouros de um campo ruidoso e polifônico, se mostraram potentes e transformadores das relações no aqui e agora. Em sala foram vivenciados instantes de construção coletiva do pensamento através do fazer, ainda que alguns dos alunos estivessem sendo catalogados como "impossíveis", e no ato em frente a câmara, foi o peso e a potência da multidão reunida em torno de uma pauta política, ambos sendo imediados por questões que emergem do encontro, sem planejamento prévio. Ambas as situações orientando e sendo reorientadas na relação. Ambas, pedagogias da imediação por natureza.

Os dois relatos, tanto o escolar quanto o grevista, buscam apontar para a complexidade das relações num contexto processual. Longe de fazer uma apologia à inercia e aceitação diante dos dados sócio-políticos que envolvem estas situações apresentadas, este trabalho se dispõe a estudar modos de estar coletivamente. Ao expandir a noção de coletivo para além dos parâmetros estabelecidos por seres humanos e acreditando na movência da vida através da relacionalidade, testemunhamos experiências nascidas no encontro e que por já haverem emergido fora dos limites das institucionalidades, criaram um ambiente diferente do habitual e ativado coletivamente sem a pré-determinação de vontades criadas antes dos acontecimentos. 


\section{References}

MANCINI, Bianca Scliar. Anotações sobre pedagogias radicais. Nupeart Revista, Florianópolis, Vol. 16, p. $11-21.2016$.

MANNING, Erin. The Minor Gesture (Tradução de André Fogliano e José Antonio R. Magalhães), Durhan: Duke University Press. 2016.

MANNING, Erin. Proposições para uma Pedagogia Radical, ou como repensar valores (Tradução Bianca Scliar Mancini). Nupeart Revista, Florianópolis, Vol. 16, p. 11-21. 2017.

MASSUMI, Brian. A arte do corpo relacional: do espelho-tátil ao corpo virtual. São Paulo: Galaxia, n.31, p. 05-21, abr. 2016.

MORAES, Daniel Silva e JARDIM, Alex Fabiano Correia. O que é uma linha de fuga? Consideração a partir do conto "A terceira margem do rio", de Guimarães Rosa. Viso Cadernos de estética aplicada. No20, p.19-30. jun. 2017.

ROLNIK, Suely. À sombra da cidadania: Alteridade, homem da ética e a reinvenção da democracia. In: MAGALHÃES, Maria Cristina Rios (Org.). Na sombra da cidade. São Paulo. Escuta, 1995, p. 143.

\section{Notas}

${ }^{1}$ Graduando do curso de licenciatura em teatro pela Universidade do Estado de Santa Catarina (UDESC). Florianópolis, Santa Catarina, Brasil. felipferro@gmail.com Concebeu e redigiu o artigo. ${ }^{2}$ Cette «fonction», en allemand est désignée par le terme Bewusstsein, soit une compréhension de la conscience comme «mouvement-vers» l'acquisition de connaissance.

${ }^{2}$ Doutora pelo Programa de Pós-Graduação em Teatro da UDESC e Universidad Veracruzana de Xalapa México (2013-2017), professora colaboradora do curso de Licenciatura em Teatro da UDESC, Florianópolis, Santa Catarina, Brasil. Colaborou na revisão do texto e orientou o processo prático aqui apresentado.

${ }^{3}$ Fala de abertura do VII Seminário Conexões: Deleuze e Cosmopolíticas e Ecologias Radicais e Nova Terra e... que aconteceu entre os dias 27 e 29 de novembro de 2017 (Unicamp). Ainda não publicada.

4 Tradução de André Fogliano e José Antonio R. Magalhães. O título Artfulness - Emergent Collectivities and Process of Individuation é parte do livro The Minor Gesture cuja autoria é da filósofa canadense Erin Manning. 